\title{
REVIEW
}

\section{Critical Review of Endovascular Treatments for Intermittent Claudication}

\author{
Michael S. Stevens \\ Class of 2012, Faculty of Medicine, Dalhousie University
}

Cystemic atherosclerosis has many manifestations, One of the most common is peripheral arterial disease. ${ }^{1}$ Peripheral arterial disease (PAD) affects over eight million people in the United States and is associated with a high risk of stroke, myocardial infarction and cardiovascular death. ${ }^{2}$ PAD is characterised by varying degrees of failure of the arterial system to deliver oxygenated blood to peripheral tissue. ${ }^{3}$ Although the majority of individuals with PAD are asymptomatic, almost $20 \%$ of individuals with PAD report the typical symptoms of intermittent claudication. ${ }^{4}$ As described by Fowkes and Gillespie, "intermittent claudication is pain in the legs due to inadequate blood flow to muscles associated with arterial narrowing (stenosis) or obstruction (occlusion). The diagnosis is based on the classic symptom of pain on walking relieved by rest." ${ }^{5}$ The objective diagnosis of claudication can be made by measuring the ankle brachial systolic pressure ratio, which is generally $<0.9$ in individuals with claudication. ${ }^{5}$ There are several other techniques used to diagnose and objectively quantify the degree of PAD, including duplex ultrasound, digital-subtraction angiography, magnetic resonance angiography and computed tomographic angiography (Table 1). Digitalsubtraction angiography is considered the gold standard for both evaluation and diagnosis of PAD. ${ }^{4}$ There are also a number of nonvascular causes of lower extremity discomfort that can present in a similar fashion to intermittent claudication, including spinal stenosis, arthritis, compartment syndrome and venous congestion (Table 2).

Mortality in individuals with intermittent claudication is most commonly due to cardiovascular disease. Therefore the treatment for intermittent claudication is focused not only on improving patients' functional tolerance and walking distance, but also on decreasing their cardiovascular risk. ${ }^{6}$ A variety of treatment options exist for individuals suffering from intermittent claudication including risk-factor modification, which involves smoking cessation, regular exercise, dietary modification, and pharmacological therapy. ${ }^{4}$ Many of these interventions, including antiplatelet therapy ${ }^{7}$ and supervised exercise programs ${ }^{8}$ have been shown to be effective in improving patient outcomes. However, revascularization is indicated for individuals who are unresponsive to pharmacologic therapy and exercise and whose claudication limits their lifestyle and ability to perform their job. This is particularly true for those with occlusion or stenosis of the superficial femoral arteries (the most common lesion associated with intermittent claudication). ${ }^{2}$ Revascularization can be performed through percutaneous transluminal angioplasty (PTA) or through arterial reconstructive surgery. ${ }^{9}$ PTA is often preferred over surgery as the approach to revascularization for a number of reasons. First, although several randomized trials have shown that mortality, amputation rates and patency rates after four years are similar for surgery and angioplasty, ${ }^{10}$ PTA has been associated with a lower risk of major complication and short-term mortality, when compared to surgery. Studies have also shown that PTA is more cost-effective than surgery if the expected patency rate for the treated vessel is equal to or greater than $30 \% .{ }^{11}$ In 2007, The TransAtlantic Inter-Society Consensus on Classification of Femoral Lesions and Recommended Approaches endorsed revascularization by PTA as the preferred approach for lesions with discrete stenoses or occlusions $(<15 \mathrm{~cm}$ long). ${ }^{12}$ Therefore, the purpose of this paper was to critically review the literature supporting the efficacy of minimally invasive endovascular procedures for the treatment of intermittent claudication. Three current endovascular procedures will be compared: angioplasty, endovascular stenting and subintimal angioplasty.

In the current literature, there is a lack of high quality randomized clinical trials comparing these interventions. PTA is the endovascular technique that has the most data and the longest follow-up. ${ }^{13}$ Angioplasty involves dilation and recanalization of an occluded or stenosed artery. ${ }^{14}$ Angioplasty is most often performed by balloon dilation, which fractures and compresses the fatty deposits in the arterial wall, leading to an increased diameter of the lumen of the vessel. A number of case studies suggested that angioplasty improved the patency of arteries in patients suffering from intermittent claudication and thus relieved symptoms over the short term, but there were also concerns over restenosis. ${ }^{15}$ Fowkes and 
Table 1. Characteristics of imaging methods used to diagnose peripheral arterial disease.

\begin{tabular}{|c|c|c|c|c|}
\hline Characteristic & Duplex Ultrasound & $\begin{array}{l}\text { Digital-Subtraction } \\
\text { Angiography }\end{array}$ & $\begin{array}{l}\text { Magnetic Resonance } \\
\text { Angiography }\end{array}$ & $\begin{array}{l}\text { Computed } \\
\text { Tomographic } \\
\text { Angiography }\end{array}$ \\
\hline Advantages & $\begin{array}{l}\text { Non-invasive; can } \\
\text { be used to visualize } \\
\text { and quantitate } \\
\text { severity of lesion. }\end{array}$ & $\begin{array}{l}\text { Gold-standard; } \\
\text { high resolution; can } \\
\text { be used to guide } \\
\text { intervention }\end{array}$ & $\begin{array}{l}\text { Non-invasive; no } \\
\text { radiation or iodinated } \\
\text { contrast material used; } \\
\text { three- dimensional }\end{array}$ & $\begin{array}{l}\text { Non-invasive; higher } \\
\text { spatial resolution } \\
\text { than with magnetic } \\
\text { resonance angiography; } \\
\text { three- dimensional }\end{array}$ \\
\hline Disadvantages & $\begin{array}{l}\text { Operator- } \\
\text { dependent; imaging } \\
\text { limited by dense } \\
\text { calcification }\end{array}$ & $\begin{array}{l}\text { Invasive; ionizing } \\
\text { radiation and } \\
\text { iodinated contrast } \\
\text { material used; two } \\
\text { dimensional }\end{array}$ & $\begin{array}{l}\text { Lower spatial } \\
\text { resolution than with } \\
\text { computed tomographic } \\
\text { angiography; } \\
\text { contraindicated } \\
\text { if patient has } \\
\text { claustrophobia; image } \\
\text { artefact if stent present }\end{array}$ & $\begin{array}{l}\text { lonizing radiation } \\
\text { ( } 25 \% \text { of dose with } \\
\text { digital-subtraction } \\
\text { angiography) and } \\
\text { iodinated contrast } \\
\text { material used; imaging } \\
\text { limited by dense } \\
\text { calcification }\end{array}$ \\
\hline
\end{tabular}

Please Note: Table adapted from White (2007) with information from the American Heart Association and the American College of Cardiology (Hirsch et al, 2005) and Schmieder and Comerota (2001).

Gillespie $^{5}$ conducted a Cochrane systematic review of randomized trials of angioplasty versus non-surgical management of intermittent claudication. The review looked at all published studies where individuals with mild to moderate intermittent claudication were randomly allocated to either angioplasty or nonsurgical treatment (such as exercise therapy) or no treatment. The authors were able to find only two randomized trials that could be used to examine this issue. Furthermore, although this review was published in 1998, the Cochrane Peripheral Vascular Diseases (PVD) Group performed a comprehensive search of studies published up until August of 2006 and found no additional randomized trials to add to the review. The PVD Group performed electronic searches of MEDLINE (from 1960 to 2006), EMBASE (from 1980 to 2006) CINAHL (1982 to 2006) and hand searched relevant journals and conference proceedings. The two trials that were included ${ }^{16,17}$ involved a total of 98 participants who were followed for six months in one study and two years in the other. The results indicated that at six months follow up there was improvement in the mean brachial systolic pressure ratio in the angioplasty intervention groups as compared to the controls. In one of the studies the angioplasty intervention group showed greater walking distances at 6 months. However, in the other study that compared angioplasty to exercise, there was no improvement in walking distance for the angioplasty intervention group over the control group. In one study, the angioplasty improved the patency of the affected arteries at two year follow up, but did not improve functional tolerance or increase walking distance when compared to controls.
In the other study, there were no significantly different outcomes in treatment and control groups at six year follow up. The authors concluded that "these limited results suggest that angioplasty may have had a short term benefit, but this may not have been sustained." However, the authors' conclusions could be questioned given the limitations of the trials reviewed, including the small numbers of participants in the trials and the potential for bias due to the lack of blinding for both the participants and the observers. In fairness to the authors, they did point out both of these limitations in the discussion of their results.

Spronk, Bosch, Veen et al. ${ }^{18}$ performed a systematic review that combined data from seven studies looking at exercise and PTA in individuals with intermittent claudication. The results of the study indicated that PTA led to an improved brachial systolic pressure ratio when compared to groups that engaged in supervised exercise but that there was no significant difference in their quality of life. A feasibility study by de Vires, Visser, de Vries et al. ${ }^{19}$ indicated that exercise was less effective than PTA and that when it was possible to perform PTA, it was more cost-effective than bypass surgery. However, aside from the studies examined in the systematic review by Fowkes and Gillespie, ${ }^{5}$ none of the other identified trials directly compared PTA with exercise therapy.

Subintimal angioplasty, another variant of PTA first described by Bolia, Miles, Brennan et al., ${ }^{20}$ has also been considered as a viable endovascular treatment for intermittent claudication. Subintimal angioplasty 
Table 2. Differentiation of intermittent claudication from "pseudoclaudication".

\begin{tabular}{|c|c|c|c|c|c|}
\hline Characteristic & $\begin{array}{l}\text { Intermittent } \\
\text { Claudication }\end{array}$ & Spinal Stenosis & Arthritis & $\begin{array}{l}\text { Venous } \\
\text { Congestion }\end{array}$ & $\begin{array}{l}\text { Compartment } \\
\text { Syndrome }\end{array}$ \\
\hline $\begin{array}{l}\text { Character of } \\
\text { discomfort }\end{array}$ & $\begin{array}{l}\text { Cramping, } \\
\text { tightness, fatigue }\end{array}$ & $\begin{array}{l}\text { Same as } \\
\text { claudication } \\
\text { OR tingling, } \\
\text { weakness, or } \\
\text { clumsiness }\end{array}$ & Aching & $\begin{array}{l}\text { Tightness, } \\
\text { bursting pain }\end{array}$ & $\begin{array}{l}\text { Tightness, } \\
\text { bursting pain }\end{array}$ \\
\hline $\begin{array}{l}\text { Location of } \\
\text { discomfort }\end{array}$ & $\begin{array}{l}\text { Buttock, hip, } \\
\text { thigh, calf, foot }\end{array}$ & $\begin{array}{l}\text { Buttock, hip, } \\
\text { thigh }\end{array}$ & Hip, knee & Groin or thigh & Calf \\
\hline $\begin{array}{l}\text { Exercise-induced } \\
\text { discomfort }\end{array}$ & Yes & Variable & Variable & After walking & $\begin{array}{l}\text { After } \\
\text { excessive } \\
\text { exercise }\end{array}$ \\
\hline Walking distance & Reproducible & Variable & Variable & Variable & Variable \\
\hline $\begin{array}{l}\text { Discomfort with } \\
\text { standing }\end{array}$ & No & Yes & $\begin{array}{l}\text { Yes, changes } \\
\text { with shift in } \\
\text { position }\end{array}$ & $\begin{array}{l}\text { Yes, changes } \\
\text { with shift in } \\
\text { position }\end{array}$ & $\begin{array}{l}\text { Yes, changes } \\
\text { with shift in } \\
\text { position }\end{array}$ \\
\hline $\begin{array}{l}\text { Relief of } \\
\text { discomfort }\end{array}$ & $\begin{array}{l}\text { Rapid relief with } \\
\text { rest }\end{array}$ & $\begin{array}{l}\text { Relief with } \\
\text { sitting or change } \\
\text { of position }\end{array}$ & $\begin{array}{l}\text { Slow relief with } \\
\text { avoidance of } \\
\text { bearing weight }\end{array}$ & $\begin{array}{l}\text { Slow relief with } \\
\text { leg elevation }\end{array}$ & $\begin{array}{l}\text { Slow relief } \\
\text { with leg } \\
\text { elevation }\end{array}$ \\
\hline Other & $\begin{array}{l}\text { Associated with } \\
\text { atherosclerosis \& } \\
\text { decreased pulses }\end{array}$ & $\begin{array}{l}\text { History of lower } \\
\text { back problems }\end{array}$ & $\begin{array}{l}\text { Discomfort at } \\
\text { joint spaces }\end{array}$ & $\begin{array}{l}\text { History of } \\
\text { deep venous } \\
\text { thrombosis, } \\
\text { signs of venous } \\
\text { congestion }\end{array}$ & $\begin{array}{l}\text { May occur in } \\
\text { athletes after } \\
\text { strenuous } \\
\text { exercise }\end{array}$ \\
\hline
\end{tabular}

Please Note: Table adapted from White (2007) with information from the American Heart Association and the American College of Cardiology (Hirsch et al, 2005) and Schmieder and Comerota (2001).

involves the creation of an extraluminal dissection that is advanced past the occlusion and then re-entered into the true lumen distally. The newly created path is then balloon dilated, and blood flow along this new path is confirmed with angiography. ${ }^{13}$ Subintimal angioplasty, also known as percutaneous intentional extraluminal recanalization (PIER), ${ }^{21}$ has become an established technique for the treatment of long and chronic arterial occlusions. ${ }^{22}$ The best evidence analyzing the efficacy of subintimal angioplasty for intermittent claudication came from Met, Van Lienden, Koelemay et al. ${ }^{22}$ who performed a systematic review of the technical and clinical outcomes of subintimal angioplasty for peripheral arterial occlusive disease. The authors searched electronic databases from the Cochrane Library, Medline, Embase, National Guideline Clearinghouse, Trip database, Bandolier and the BMJ Clinical Evidence, reviewing literature from 1966 until May of 2007. A total of 1549 participants from 23 cohort studies were included in the systematic review. The studies were divided into three subgroups based on the site of the lesion (i.e., femoral-popliteal, crural or both) and the clinical grade of their PAD: intermittent claudication, critical limb ischemia or a mixture of the two. For purposes of this paper, the studies of primary interest were those that focused on individuals with intermittent claudication affecting the femoralpopliteal arteries. The results of the 23 combined studies included in the review indicated that "subintimal angioplasty seems to have lower patency rates than surgery".22 However, no comparative studies had been conducted to include in the review. In terms of the efficacy of subintimal angioplasty for individuals with intermittent claudication, only two studies that were analyzed included only individuals with intermittent claudication. The results of those two studies indicated a clinical success rate of $58 \%$. Clinical success was defined by the authors as resolution or improvement in claudication, relief of pain at rest, healing of ulcers, or healing of minor amputations which were required for gangrene and non-healing wounds after previous amputation. The two studies also reported a primary 
patency of $56 \%$ after one year and a primary assisted patency of $56 \%$ after three years. By comparison, the patency rates following femoral-popliteal PTA at one, three, and five years have been reported to be $87 \%, 69 \%$ and $55 \%$ respectively. ${ }^{10}$ Therefore, the authors of the review were correct in concluding that due to the lower patency rates associated with subintimal angioplasty as compared to PTA, it should be offered with reserve to patients suffering from intermittent claudication. Although the systematic review by Met, Van Lienden, Koelemay et al. ${ }^{22}$ provided the best evidence available regarding the efficacy of subintimal angioplasty on PAD and intermittent claudication, it is difficult to base any strong conclusions, let alone clinical decisions, on the review given its limitations. First of all, there were no randomized control trials to include in the systematic review. The only published studies were observational case series. The authors of the review indicated that for many studies included in the review, the selection procedure for the treatment was unclear. In addition, there was so much clinical heterogeneity that it obstructed the reviewers from performing a meta-analysis. The authors also pointed out in their discussion that there were no consistent standards for reporting results between studies. Different studies used different outcome measures, different outcome definitions, and different statistical methods to determine their outcomes. Given the methodological flaws within the studies, the lack of standardization between studies, and the case series design of the studies included, it is difficult to make any significant conclusions about the role of subintimal angioplasty in treating intermittent claudication. However, as poor as the evidence was, the systematic review of all of the literature up to May of 2007 provided no support for the use of subintimal angioplasty over PTA.

The use of endovascular stents is the third minimally invasive technique that has been considered as an alternative treatment for individuals suffering from intermittent claudication. Originally described by Dotter, ${ }^{23}$ endovascular stents provide structural support to an injured vessel. Stents are classified into two types: self-expanding or balloon-expandable catheter. ${ }^{24}$ The first high quality review that examined the efficacy of using endovascular stents following PTA compared to PTA alone was a Cochrane review by Bachoo and Thorpe ${ }^{9}$ published in 2002. The authors examined all randomized trials comparing PTA alone to PTA combined with intra-luminal stent placement for treatment of intermittent claudication. The reviewers utilized the search strategy developed by the Cochrane Peripheral Vascular Diseases Group including electronic searches of databases such as
MEDLINE (1966 to 2002), and EMBASE (1980 - 2002). Only two randomized trials met the inclusion criteria and were included in the review. The total sample size for the review was 104 participants. The participants in both studies had femoro-popliteal disease. The participants who received a stent following PTA received a Palmaz balloon-expandable stent. None of the participants received a self-expanding stent. The results of the review indicated that there was no clinically significant advantage or disadvantage to the use of the Palmaz endovascular stent in terms of arterial patency. This systematic Cochrane review was updated in 2010 by Bachoo and Thorpe, ${ }^{25}$ however, no additional studies met the inclusion criteria. Therefore, Bachoo and Thorpe's ${ }^{9}$ initial 2002 conclusions remained unchanged in their 2010 update. ${ }^{25}$ Bachoo and Thorpe's ${ }^{9}$ systematic review revealed no compelling evidence to preferentially support the use of either PTA or stenting, in terms of the studies' primary or secondary outcome measures. Primary outcome measures included: reocclusion/restenosis rates after endovascular intervention and maximum walking distance. Secondary outcome measures included the Edinburgh Claudication Questionnaire ${ }^{26}$ and clinical endpoints such as post-intervention morbidity, length of hospital stay, failed treatment, amputation rates, post-operative mortality, ankle brachial pressure index, intra-arterial pressure changes, changes in blood flow rates, health status measures, cost utility, and cost effectiveness. There were a number of limitations of the studies reviewed including a lack of blinding of the observers and uncertainty about whether or not the participants were blinded. The studies also had small sample sizes with no a priori power calculation and both studies reported outcomes after a relatively short follow-up period of 12 months. Another limitation of the studies, discussed by the authors, was the use of the older balloon-expandable stents as opposed to the newer self-expanding stents. The authors of the review indicated that the manufacturers of the newer self-expanding stents had made claims that the self-expanding stents were less prone to in-stent restenosis due to neointimal hyperplasia.

Therefore, as the technology improved, a randomized trial conducted by Schillinger, Sabeti, Loewe et al. ${ }^{27}$ was performed to examine whether primary implantation of self-expanding nitinol stents would provide better outcomes than PTA with optional secondary stenting for individuals suffering from occlusion or stenosis of the superficial femoral artery. The authors of the trial randomly assigned 53 participants with severe claudication or chronic limb ischemia to the group that would receive PTA alone and 51 participants with severe 
claudication or chronic limb ischemia to the group receiving primary nitinol stent implantation. To be included in the trial, participants had to be experiencing symptomatic PAD with severe intermittent claudication (Rutherford stage 3), chronic critical limb ischemia with pain while the participant was at rest (Rutherford stage 4), or chronic critical limb ischemia with ischemic ulcers (Rutherford stage 5). ${ }^{27}$ In total, the trial involved 104 randomly assigned participants. The primary outcome was restenosis, which was defined as stenosis of at least $50 \%$ of the luminal diameter in the treated segment at six months and at 12 months. ${ }^{27}$ There were also a number of secondary clinical outcomes including the Rutherford stage of peripheral- artery disease, ${ }^{28}$ an individuals' maximum walking capacity on a treadmill and the participants' resting ankle-brachial index. The results of the trial indicated that at six months there was a reduced rate of restenosis in the nitinol stent group (24\%) when compared to the PTA group (43\%) $(\mathrm{p}=0.05)$ and that at one year there was an even greater significant difference with $37 \%$ restenosis in the nitinol stent group versus $63 \%$ in the PTA group ( $\mathrm{p}=0.01)$. The results of the trial also indicated that the maximum walking distance and the ankle-brachial index were significantly better after one year in the nitinol stent group, compared to the group that received PTA alone. Furthermore, there were no major complications in either group. The results of the study lead the authors to conclude that "primary implantation of self-expanding nitinol stents for the treatment of lesions in the superficial femoral artery was associated with superior anatomical and clinical intermediate-term results in comparison with the currently recommended approach of balloon angioplasty with optional secondary stenting." ${ }^{27}$

Although the study by Schillinger, Sabeti, Loewe et al. ${ }^{27}$ published follow-up results of the participants for only one year, a second article by Schillinger, Sabeti, Dick et al. ${ }^{29}$ did provide the follow-up results of 98 (94\%) of the 104 original participants after two years. It was found after two year follow up that there was a $45.7 \%$ (21 of 46) rate of restenosis in the nitinol stent group versus a 69.2\% (36 of 52) rate of restenosis in the PTA group with optional stenting $(\mathrm{P}=0.03)$. The two year follow up data provided further evidence of a sustained benefit of primary self-expanding nitinol stents over PTA with optional stenting for patients with superficial femoral artery occlusions. Although Schillinger, Sabeti, Dick et al. ${ }^{29}$ also reported a trend toward clinical benefit for the nitinol stent group compared to the PTA group with optional stenting, there was no statistically significant difference between the two groups at two years with respect to their walking capacity on a treadmill or their ankle brachial index values. Overall, Schillinger,
Sabeti, Loewe et al.'s ${ }^{27}$ randomized trial employed a rigorous methodology and was of a high quality, and the results of that study along with the two year follow up results provided by Schillinger, Sabeti, Dick et al. ${ }^{29}$ provided some evidence that nitinol stenting may be preferable to PTA for patients with severe intermittent claudication. However, the study provided only one small randomized trial from which to draw conclusions.

To examine the issue further a systematic review and meta-analysis comparing PTA with stenting for the treatment of femoro-popliteal occlusive disease was performed by Mwipatayi, Hockings, Hofmann et al. $^{30}$ The authors performed a systematic review of the published literature in PUBMED, MEDLINE and EMBASE between September 2000 and January 2007. The authors stated that they restricted their literature search to this period because there had been two previous meta-analyses that included both PTA and stenting published in $1994^{31}$ and in $2001^{32}$ and because the technology of PTA and stenting had advanced rapidly since the turn of the century. The authors found only seven studies that met their inclusion criteria. All seven were randomized controlled trials comparing the outcome of PTA to that of stenting of the femoropopliteal segment. One of the studies included was Schillinger, Sabeti, Loewe et al'.s ${ }^{27}$ randomized trial described above. The seven studies included in the review involved 934 participants in total. The authors performed a meta-analysis of the results of the seven trials. Based on the results of the meta-analysis, the authors concluded that stent implantation in femoropopliteal occlusive disease does not increase the patency rate when compared with PTA after one year. Interestingly, only two of the seven trials included in the meta-analysis compared self-expanding stents to PTA, with the results indicating "slightly better result toward the stent group but not overall statistically significant results." ${ }^{30}$ The authors pointed out a number of limitations of their systematic review including the fact that none of the studies followed up on the participants for a prolonged period of up to four years. They reported that a longer term follow-up may provide different results, possibly indicating improved outcomes for participants receiving stents. The authors also noted that all nitinol stents are not the same, some are much more flexible and others more rigid. They commented that differences in stent technology may lead to a difference in outcomes for patients.

The preceding literature review was intended to summarize and critically evaluate the published literature supporting the efficacy of three minimally invasive endovascular techniques: percutaneous 
Table 3. TransAtlantic Inter-Society consensus on the classification of femoral lesions and recommended approaches when revascularization is planned

\begin{tabular}{|c|c|c|}
\hline Lesion Type & Characteristics & Recommended Treatment \\
\hline $\bar{A}$ & $\begin{array}{l}\text { Single stenosis } \leq 10 \mathrm{~cm} \text { long; Single occlusion } \leq 5 \mathrm{~cm} \\
\text { long }\end{array}$ & $\begin{array}{l}\text { Percutaneous transluminal angioplasty } \\
\text { strongly preferred }\end{array}$ \\
\hline B & $\begin{array}{l}\text { Multiple lesions, each } \leq 5 \mathrm{~cm} \text { long; Single lesion } \leq 15 \\
\mathrm{~cm} \text { long, not involving the popliteal artery below } \\
\text { the knee; Single or multiple lesions in the absence } \\
\text { of continuous tibial vessels for distal bypass; Heavily } \\
\text { calcified occlusion } \leq 5 \mathrm{~cm} \text { long; Single popliteal } \\
\text { stenosis }\end{array}$ & $\begin{array}{l}\text { Percutaneous transluminal angioplasty } \\
\text { generally preferred }\end{array}$ \\
\hline $\mathrm{C}$ & $\begin{array}{l}\text { Multiple lesions } \leq 15 \mathrm{~cm} \text { long; Recurrent lesions after } \\
\text { two endovascular interventions }\end{array}$ & $\begin{array}{l}\text { Percutaneous transluminal angioplasty } \\
\text { or surgery, depending on the risk-benefit } \\
\text { ratio }\end{array}$ \\
\hline $\mathrm{D}$ & $\begin{array}{l}\text { Occlusions > } 20 \mathrm{~cm} \text { long; Occlusion of the popliteal } \\
\text { or tibial-peroneal vessels }\end{array}$ & Surgery generally preferred \\
\hline
\end{tabular}

transluminal angioplasty, subintimal angioplasty and primary implantation of endovascular stents for the treatment of intermittent claudication. However, although the TransAtlantic Inter-Society Consenus recommends an endovascular-first for occlusions less than $20 \mathrm{~cm}$ long strategy (Table 2), open surgical reconstruction should not be automatically discounted. As Perera and Lyden $^{13}$ pointed out, the reduced mortality and morbidity associated with endovascular techniques may come at a cost of decreased durability and an increased need for reintervention. In many cases, an open surgical reconstruction can follow an endovascular procedure that has failed and vice versa. ${ }^{13}$

There are a number of purported advantages and disadvantages to these endovascular procedures. Percutaneous transluminal angioplasty (PTA) is a minimally invasive technique that can lead to an immediate increase in the calibre of the lumen of the artery. ${ }^{14}$ PTA has also been shown to be versatile, ${ }^{33}$ with high patient preference and low complication rates of around $6 \% .^{30}$ The use of PTA specifically for treatment of superficial femoral artery occlusions has been associated with initial technical success rates of 95\% with a low risk of complications. ${ }^{34}$ However, there are also limitations associated with the use of PTA. Restenosis has been shown to occur in $40 \%$ to $60 \%$ of the treated segments within the artery within one year of the procedure..$^{34}$ In longer segments $(>10 \mathrm{~cm})$ even poorer efficacy has been reported, with restenosis of over $70 \%$ in segments treated with PTA within the first year. ${ }^{35}$ PTA can also lead to a flow limiting dissection after balloon inflation. ${ }^{27}$
Due to the limitations of PTA, additional endovascular techniques have been attempted, including subintimal angioplasty. Being a variant of PTA, it should come as no surprise that many of the advantages are the same as PTA. As with PTA, subintimal angioplasty is a minimally invasive technique that allows patients to become ambulatory shortly after the procedure. In addition, failed subintimal angioplasty (like PTA) does not preclude the potential for later open surgical reconstruction. ${ }^{36}$ However, there are a number of disadvantages to this approach, including a concern that subintimal angioplasty is difficult to learn. ${ }^{22}$ In addition, observational studies have indicated lower primary patency after one year than what has been reported following PTA. ${ }^{22}$ Finally, there are no randomized trials comparing subintimal angioplasty with PTA or with surgery and the long term results are unknown. ${ }^{22}$

Clinicians have attempted to improve the outcomes following PTA for patients with intermittent claudication by using endovascular stents. Endovascular stents have the advantage of being able to avoid many of the problems of PTA including flow limiting dissection after balloon inflation, early elastic recoil and residual stenosis. ${ }^{27}$ As a result, they have the potential to be used for longer and more calcified lesions ${ }^{27}$ Although initial studies comparing balloon-expandable stents with PTA showed no clinically significant advantage of stenting over PTA, ${ }^{9}$ early studies of self-expanding nitinol stents demonstrated patency rates of greater than $85 \%$ at 18 months. ${ }^{37}$ With regard to self-expanding stents, "nitinol stents have demonstrated greater radial force, increased resistance to crush deformity, and reduced foreshortening, which allows for greater precision of 
Table 4. Summary of major systematic reviews of endovascular treatments for intermittent claudication.

\begin{tabular}{|c|c|c|c|c|c|}
\hline Authors & $\begin{array}{l}\text { Endovascular } \\
\text { Treatment Evaluated }\end{array}$ & Study Design & $\begin{array}{l}\text { \# Studies/Total } \\
\text { sample size }\end{array}$ & Follow Up & Results \\
\hline $\begin{array}{l}\text { Fowkes \& } \\
\text { Gillespie (1998) }\end{array}$ & $\begin{array}{l}\text { Angioplasty vs. non- } \\
\text { surgical management }\end{array}$ & $\begin{array}{l}\text { Systematic review } \\
\text { of randomized } \\
\text { trial* }\end{array}$ & $2 / 98$ & 6 months -6 years & $\begin{array}{l}\text { At 6-months significant } \\
\text { clinical benefit of PTA over } \\
\text { non-surgical management. } \\
\text { At 2-years PTA group had } \\
\text { superior artery patency, } \\
\text { but demonstrated no } \\
\text { significant clinical benefit. }\end{array}$ \\
\hline $\begin{array}{l}\text { Bachoo \& } \\
\text { Thorpe (2002) }\end{array}$ & $\begin{array}{l}\text { Angioplasty vs. } \\
\text { endovascular stents }\end{array}$ & $\begin{array}{l}\text { Systematic review } \\
\text { of randomized } \\
\text { trial* }\end{array}$ & $2 / 104$ & 1 year & $\begin{array}{l}\text { At 1-year no significant } \\
\text { clinical advantage of stents } \\
\text { compared to PTA alone. }\end{array}$ \\
\hline $\begin{array}{l}\text { Mwipatayi, } \\
\text { Hockings, \& } \\
\text { Sieunarine } \\
\text { (2008) }\end{array}$ & Angioplasty vs. stents & $\begin{array}{l}\text { Systematic review } \\
\text { and meta-analysis } \\
\text { of randomized } \\
\text { controlled trials }\end{array}$ & $7 / 934$ & 6 months -4 years & $\begin{array}{l}\text { At 1-year stent placement } \\
\text { did not increase patency } \\
\text { rate when compared to } \\
\text { PTA alone. }\end{array}$ \\
\hline $\begin{array}{l}\text { Met, Van } \\
\text { Lienden, } \\
\text { Koelemay, Bipat, } \\
\text { Legemate, \& } \\
\text { Reekers (2008) }\end{array}$ & Subintimal angioplasty & $\begin{array}{l}\text { Systematic review } \\
\text { of case series } \\
\text { (observational } \\
\text { studies) }\end{array}$ & $23 / 1549$ & 1 year & $\begin{array}{l}\text { At 1-year subintimal } \\
\text { angioplasty resulted in } \\
\text { lower arterial patency } \\
\text { rates when compared to } \\
\text { published rates for PTA } \\
\text { alone. }\end{array}$ \\
\hline
\end{tabular}

*Please Note: These studies were Cochrane Systematic Reviews

placement when compared with the prior generation of stainless-steel stents." ${ }^{13}$ However, despite the beneficial findings of these early studies, nitinol self-expanding stents were also shown to have a number of significant disadvantages including late restenosis due to intimal hyperplasia. ${ }^{13}$ More recently, studies have also reported late stent fractures in self-expanding nitinol stents leading to increased risk of restenosis. ${ }^{38}$

After reviewing the literature on the efficacy of the endovascular procedures used to treat intermittent claudication, it is clear that a great deal of controversy remains. There continues to be a need for additional high quality randomized controlled trials with longer term follow-up, adequate numbers of participants, and power to properly assess the efficacy of these endovascular techniques.

Despite some recent evidence to suggest that primary implantation of nitinol stents may provide superior results to PTA for patients with severe intermittent claudication, ${ }^{27}$ overall, both previous ${ }^{9}$ and current reviews of the literature ${ }^{30}$ have concluded that stenting provides no advantage over PTA for this patient population. Currently the TransAtlantic Inter-Society Consensus recommends the use of PTA for short lesions of the superficial femoral artery (Table 3) and has advised that stents be used only in bailout situations ${ }^{12}$.

A summary of the published systematic review studies regarding the efficacy of endovascular techniques for the treatment of intermittent claudication has been provided in Table 4. Upon evaluation of these systematic reviews, it is evident that there are a number of shortcomings in the current research. Future research should focus on addressing these shortcomings.

One concern mentioned by a number of authors (e.g, Bachoo and Thorpe), ${ }^{9}$ was that many of the studies examined the efficacy of these endovascular techniques using a mixed population of participants. In many studies, participants with intermittent claudication were combined with patients with critical limb ischemia. Furthermore, trials differed in their participants' degree of ischemia or intermittent claudication, and the way in which they were quantified. This made comparison of the outcomes difficult and it also hindered the generalizability of the results. In the future, studies examining the efficacy of endovascular techniques on patients with intermittent claudication should include only participants with intermittent claudication and should use a standardized method of quantifying and reporting the extent of the patients' claudication. 
Another problem pointed out by Bachoo and Thorpe 9 was that many studies combined the results of the endovascular procedures for segments of different arteries such as the common iliac, superficial femoral and popliteal, as opposed to analyzing them separately. Therefore, there was no way of determining whether or not one technique might be favourable for a particular vessel. Future studies should address this issue by analyzing the results for different arteries independently.

Another major criticism of virtually all of the studies were the small sample sizes of each study, which provided little power from which to draw clinically significant conclusions (e.g., Fowkes \& Gillespie). ${ }^{5}$ Larger studies in the future would lend more weight to researchers' findings and help to more clearly demonstrate the efficacy of each therapeutic approach.

The authors of the systematic reviews ${ }^{5,9,22,30}$ all reported that there was a lack of standardization across studies in terms of how lesions and outcomes were classified and how results were analyzed and reported. Bachoo and Thorpe $^{9}$ suggested that all target lesions be classified in terms of anatomic grades of disease, severity, extent and length based on the Trans-Atlantic Inter Society Consensus (TASC) classification. In addition, Rutherford, Baker, Ernest et al., ${ }^{28}$ published a classification scheme that could be used to differentiate patients with critical limb ischemia from patients with intermittent claudication. Also, a number of the studies used different means of quantifying arterial patency (e.g., the ankle-brachial index, computed tomographic angiography, digital subtraction angiography, duplex ultrasonography or magnetic resonance angiography). Given that the primary outcome measure reported in these studies is arterial patency, the importance of a standardized assessment of arterial patency cannot be overstated. Bachoo and Thorpe ${ }^{9}$ also pointed out that not all of the studies used clinically relevant outcome measures, including measurements of quality of life, standardized walking tests and disease specific health questionnaires. Along with arterial patency it is important that future research also quantify the functional impact of a particular intervention. In order to accurately compare and contrast the efficacy of future studies, a standardized system should be used by all investigators to assess, quantify and report their results.

Bachoo and Thorpe ${ }^{9}$ highlighted two other concerns that were mentioned by a number of review authors. First, they recommended that future researchers ensure that all participants in a particular study are provided with similar pre and post intervention pharmacotherapy. Many of the studies reviewed failed to control for, or even report, the pre and post intervention medications taken by the participants. This is despite the fact that medications such as antiplatelets have been shown to significantly lower the risk of morbidity and mortality due to vascular causes. ${ }^{7}$ Bachoo and Thorpe ${ }^{9}$ also recommended that future participants be provided with similar advice regarding lifestyle changes and equal management of known risk factors in order to control for other potential confounding factors.

Finally, there is a clear lack of quality randomized trials in the published literature from which to compare PTA, subintimal angioplasty and stenting and their role in the treatment of intermittent claudication. In the case of subintimal angioplasty for example, Met, Van Lieden, Koelemay et al. ${ }^{22}$ failed to identify even one randomized controlled trail comparing subintimal angioplasty to other endovascular interventions or even to surgery. The other major limitation in the published research is the fact that there is currently no long-term comparative data regarding the role of these alternative techniques. ${ }^{36}$ There is a very real need for larger, more rigorous, long-term efficacy studies to ensure optimal care for patients suffering from intermittent claudication. In order to accurately assess which endovascular technique should be applied to a particular patient, clinicians must rely on the best evidence available. It appears that at this time, there is very little high quality research to help guide their decision.

\section{References}

1. Pasternak RC, Criqui MH, Benjamin EJ, Fowkes GR, Isselbacher EM, McCullough PA, Wolf PA, Zheng ZJ. Atherosclerotic Vascular Disease Conference: Writing Group I: Epidemiology. Circulation 2004;109:2605-2612.

2. Hirsch AT, Haskal ZJ, Hertzer NR et.al. ACC/AHA 2005 Guidelines for the management of patients with peripheral arterial disease (lower extremity, renal mesenteric, and abdominal aortic): Executive Summary. A Collaborative Report from the American Association for Vascular Surgery/Society for Vascular Surgery Society for Cardiovascular Angiography and Interventions, Society for Vascular Medicine and Biology, Society of Interventional Radiology, and the ACC/AHA Task Force on Practice Guidelines (Writing Committee to Develop Guidelines for the Management of Patients With Peripheral Arterial Disease). J Am Coll Cardiol 2005;47:1-192.

3. Lovell M, Harris K, Forbes T, Twillman G, Abramson B, Criqui MH, Schroeder P, Mohler ER, \& Hirsh AT. Peripheral Arterial Disease: Lack of awareness in Canada. Can J Cardiol 2009;25:2945.

4. White C. Intermittent Claudication. N Engl J Med 2007;356:12411250.

5. Fowkes G, Gillespie IN. Angioplasty (versus non surgical management) for intermittent claudication. Cochrane Database Syst Rev 1998; 2: Art. No.:CD000017. DOI: 10.1002/14651858. CD000017. 
6. Arain FA, Cooper Jr LT. Peripheral Arterial Disease: Diagnosis and management. Mayo Clin Proc 2008;83:944-950.

7. Antithrombotic Trialists' Collaboration. Collaborative metaanalysis of randomized trials of antiplatelet therapy for prevention of death, myocardial infarction, and stroke in high risk patients. BMJ 2002;324:71-86.

8. Leng GC, Fowler B, Ernst E. Exercise for intermittent claudication. Cochrane Database Syst Rev 2000;2:Art. No.:CD000990 DOI: 10.1002/14651858.CD000990.

9. Bachoo P, Thorpe PA. Endovascular stents for intermittent claudication. Cochrane Database Syst Rev 2002;4:Art. No.:CD003228. DOI: 10.1002/14651858.CD003228.

10. Clark TW, Groffsky JL, Soulen MC. Predictors of long-term patency after femoropopliteal angioplasty: results from the STAR registry. N Engl J Med 2007;12:923-933.

11. Lundgren F, Dahllof AG, Lundholm K, Schersten T, Volkmann R. Intermittent claudication - surgical reconstruction or physical training? A prospective randomized trial of treatment efficiency. Ann Surg 1989;209:346-355.

12. Norgeen, L, Hiatt, W.R, Dormandy, J.A, Nehler, M.R, Harris, K.A, Fowkes, FGR. Inter-Society consensus for the management of Peripheral Arterial Disease (TASC II). Eur J Vasc Endovasc Surg 2007;33, Supplement: S1-S75.

13. Perera GB, Lyden SP. Current Trends in Lower Extremity Revascularization. Surg Clin North Am 2007;87:1135-1147.

14. Belli AM, Jackson JE, Allison DJ. Interventional radiological procedures. In: Clement DL, Shepard JT, ed(s). Vascular disease in the limbs: Mechanisms and principles of treatment. Saint Louis: Mosby Year Book, 1993;239-258.

15. Price JF, Fowkes FGR. Effectiveness of percutaneous angioplasty for lower limb artherosclerosis. In: Greenhalgh RM, Fowkes FGR, ed(s). Trials and tribulations in vascular surgery. London: WB Saunders, 1996.

16. Whyman MR, Fowkes FGR, Kerracher EMG, Gillespie IN, Lee AJ, Housley E, Ruckley CV. Is intermittent claudication improved by percutaneous transluminal angioplasty? A randomized controlled trial. J Vasc Surg 1997;26:551-557.

17. Creasy TS, McMillan PJ, Fletcher EWI, Collin J, Morris PJ. Is percutaneous transluminal angioplasty better than exercise for claudication? Preliminary results of a prospective randomised trial. Eur J Vasc Surg 1990;4:135-140.

18. Spronk S, Bosch JL, Veen HF, den Hoed PT, Hunink MG. Intermittent claudication: Functional capacity and quality of life after exercise training or percutaneous transluminal angioplasty - systematic review. Radiology 2005;235:833-842.

19. de Vries SO, Visser K, de Vries JA, Wong JB, Donaldson MC, Hunink MG. Intermittent claudication: Cost-effectiveness of revascularization versus exercise therapy. Radiology 2002;222:2536.

20. Bolia A, Miles KA, Brennan J, Bell PRF. Percutaneous transluminal angioplasty of occlusions of the femoral and popliteal arteries by subintimal dissection. Cardiovasc Intervent Radiol 1990;13:357363.

21. Reekers JA, Kromhout JG, Jacobs MJ. Percutaneous intentional extraluminal recanalisation of the femoropopliteal artery. Eur J Vasc Surg 1994;8:723-728.

22. Met R, Van Lienden KP, Koelemay MJW, Bipat S, Legemate DA, Reekers JA. Subintimal angioplasty for peripheral arterial occlusive disease: A systematic review. Cardiovasc Intervent Radiol 2008;31:687-697.

23. Dotter CT. Judkins MP. Transluminal treatment of arteriosclerotic obstruction. Description of a new technique and a preliminary report of its application. Radiology 1989;172:904-920.

24. Carreira JM, Reyes R, Gude F, Gorriz E, Gallardo L, Pardo MD, Hermida M. Long-term follow-up of Symphony nitinol stents in iliac arteriosclerosis obliterans. Minim Invasive Ther Allied Technol 2008;17:34-42.
25. Bachoo P, Thorpe PA, Maxwell H, Welch K. Endovascular stents for intermittent claudication. Cochrane Database Syst Rev 2010;Jan20:(1):CD003228.

26. Leng GC, Fowkes FG. The Edinburgh claudication questionnaire: An improved version of the $\mathrm{WHO} /$ Rose questionnaire for use in epidemiological surveys. J Clin Epidemiol 1992;45:1101-1109.

27. Schillinger M, Sabeti S, Loewe C, Dick P, Amighi J, Mlekusch W, Schlager O, Cejna M, Lammer J, Minar E. Balloon angioplasty versus implantation of nitinol stents in the superficial femoral artery. N Engl J Med 2007;354:1879-1888.

28. Rutherford RB, Baker JD, Ernst C, Johnston KW, Porter JM, Ahn $\mathrm{S}$, Jones DN. Recommended standards for reports dealing with lower extremity ischemia. J Vasc Surg 1997;26(3):517-38.

29. Schillinger M, Sabeti S, Dick P, Amighi J, Mlekusch W, Schlager O, Loewe C, Cejna M, Lammer J, Minar E. Sustained benefit at 2 years of primary femoropopliteal stenting compared with balloon angioplasty with optional stenting. Circulation 2007;115:27452749.

30. Mwipatayi BP, Hockings A, Sieunarine K. Balloon angioplasty compared with stenting for treatment of femoropopliteal occlusive disease: A meta-analysis. J Vasc Surg 2008;47:461-469.

31. Hunink MG. Wong JB. Meta-analysis of failure-time data with adjustments for covariates. Med Decis Making 1994;14:59-70.

32. Muradin GS, Bosch JL, Stijnen T, Hunink MG. Balloon dilation and stent implantation for treatment of femoropopliteal arterial disease: Meta-analysis. Radiology 2001:221:137-145.

33. Ahn SS, Eton D, Moore WS. Endovascular surgery for peripheral arterial occlusive disease. A critical review. Ann Surg 1992;216:316.

34. Dormandy JA. Rutherford B. Management of peripheral arterial disease (PAD). J Vasc Surg 2000;31:S1-S296.

35. Capek P, McLean GK, Berkowitz HD. Femoropopliteal angioplasty: Factors influencing long-term success. Circulation 1991;83(Supp 2):170-180.

36. Sandford RM, Bown MJ, Sayers RD, London J, Naylor NAR, McCarthy M.J. Is infrainguinal bypass grafting successful following failed angioplasty? Eur J Vasc Endovasc Surg 2007;34:2934.

37. Henry M, Amor M, Betar I, Henry I, Porte JM, Mentre B, Tricoche O, Ethevenot G. Clinical experience with a new nitinol selfexpanding stent in peripheral artery disease. J Endovasc Surg 1996;3:369-379.

38. Duda SH, Bosiers M, Lammer J, Scheinert D, Zeller T, Oliva V, Tielbeek A, Anderson J, Wiesinger B, Tepe G, Lansky A, Jaff MR, Mudde C, Tielemans H, Beregi JP. Drug-eluting and bare nitinol stents for the treatment of atherosclerotic lesions in the superficial femoral artery: Long-term results from the SIROCCO trial. J Endovasc Ther 2006;13:701-710.

39. Lyden SP, Shimshak TM. Contemporary endovascular treatment for disease of the superficial femoral and popiteal arteries: An integrated device-based strategy. J Endovasc Ther 2006:13(Supp 2):41-51. 